\title{
A Comparative Study of Intrathecal Injection of Bupivacaine Alone or with Fentanyl, Clonidine, and Neostigmine in Lower Abdominal Surgeries
}

\author{
Elsayed Mohamed Abdelzaam* ${ }^{*}$, Ahmed Hamdy Abd Elrahman \\ Department of Anesiology, Faculty of Medicine, Benha University, Benha, Egypt \\ Email: ^ALSAYED.ABDELZAIM@fmed.bu.edu.eg, ahmed76hamdy@yahoo.com
}

How to cite this paper: Abdelzaam, E.M. and Elrahman, A.H.A. (2019) A Comparative Study of Intrathecal Injection of Bupivacaine Alone or with Fentanyl, Clonidine, and Neostigmine in Lower Abdominal Surgeries. Open Journal of Anesthesiology, 9, 83-98.

https://doi.org/10.4236/ojanes.2019.94009

Received: March 19, 2019

Accepted: April 27, 2019

Published: April 30, 2019

Copyright $\odot 2019$ by author(s) and Scientific Research Publishing Inc. This work is licensed under the Creative Commons Attribution International License (CC BY 4.0).

http://creativecommons.org/licenses/by/4.0/

\begin{abstract}
Background: Anesthesiologists are responsible for the development of pain services in the current era. Hence ideal adjuvants that can be used with bupivacaine for stable intraoperative conditions and prolonging the postoperative analgesia with fewer side effects are being investigated. Opioids, despite useful as adjuvants, are associated with undesirable side effects. Aim of the work: The study was done to compare analgesic efficacy and hemodynamic of intrathecal injection of bupivacaine alone or with fentanyl, clonidine, and neostigmine in lower abdominal surgeries, over the first 24 postoperative hours, in a randomized, double-blind, and clinical trial. Methods: $100 \mathrm{~Pa}-$ tients were randomized into four equal groups, 25 patients in each group; Group B patients received $2.5 \mathrm{ml}$ of $0.5 \%$ hyperbaric bupivacaine and $0.5 \mathrm{ml}$ of normal saline. Group BF patients received $2.5 \mathrm{ml}$ of $0.5 \%$ hyperbaric bupivacaine with ( 25 mics) of fentanyl. Group BC patients received $2.5 \mathrm{ml}$ of $0.5 \%$ hyperbaric bupivacaine with $0.5 \mathrm{ml}$ (75 mics) of clonidine. Group BN patients received $2.5 \mathrm{ml}$ of $0.5 \%$ hyperbaric bupivacaine with $0.1 \mathrm{ml}$ of neostigmine (50 mics) and $0.4 \mathrm{ml}$ of normal saline. Intrathecal anesthesia was done with a recording of parameters intraoperative and the post-operative period. Each patient was assessed for hemodynamic parameters and effective analgesia in operation, and presence of complications (nausea, vomiting, sedation and pruritus) visual analogue pain score (VAS) postoperatively by a blinded investigator in the post-anesthesia care unit (PACU) and at 1, 2, 3, 4, 812,18 and $24 \mathrm{~h}$ postoperatively. Results: The postoperative analgesia is more effective with group $\mathrm{BC}$ (the gold standard) than group $\mathrm{B}$, group $\mathrm{BF}$, and group $\mathrm{BN}$. As regard complications during the study in all groups, complications as nausea, and vomiting were mainly with group $\mathrm{BN}$; hypotension was primarily in group BC. Conclusion: Bupivacaine clonidine, bupivacaine neostigmine, and bupivacaine fentanyl intrathecal anesthesia produced a longer duration
\end{abstract}


of postoperative analgesia after lower abdominal surgery in patients than bupivacaine alone. Bupivacaine clonidine mixture had the most extended period of analgesia, but with hypotension. So bupivacaine fentanyl mixture with moderate duration of analgesia and minimal side effects is most safe for a patient.

\section{Keywords}

Intrathecal, Bupivacaine, Fentanyl, Neostigmine, Clonidine

\section{Introduction}

Transmission of pain from peripheral tissues to higher centers in the brain is adjusted in the dorsal horn of the spinal cord. Incoming messages can be increased or decreased by different transmitters derived from either primary afferent $\mathrm{A}$ delta and $\mathrm{C}$ fibers, interneurons or descending bulbospinal fibers. After noxious stimulation, excitatory neurotransmitters are released from afferent fibers. Compensatory inhibitory neurotransmitters include (norepinephrine and acetylcholine). Therefore, an interplay between excitatory and inhibitory spinal neuronal systems will detect the message conveyed to higher levels of the central nervous system. Increased understanding in spinal processing of pain has to lead to the development of specific drugs that inhibit pain transmission without motor blockade [1].

Intrathecal opioid and local anesthetic combination are popular for analgesia because of rapid, effective pain relief, but the duration of analgesia is limited. This study will be done to detect whether the addition of, fentanyl and neostigmine to intrathecal bupivacaine will increase the length of analgesia without increasing complications for patient [2].

Bupivacaine is the most commonly employed local anesthetic for a subarachnoid block but has a limited duration of action. Perioperative hemodynamic status is also a concern. Opioids, in spite of useful as adjuvants, are associated with undesirable complications. Therefore, ideal adjuvants that can be used with bupivacaine for stable intraoperative conditions and prolonging the postoperative analgesia with fewer complications are being investigated [3].

Intrathecal local anesthetic acts by inhibiting voltage-gated sodium channels in the spinal cord, which interferes with afferent and efferent sensory and motor impulses. The degree of sensory and motor block depends on technique, agent, and dose administered. Opioids act in the intrathecal space by activating opioid receptors in the dorsal gray matter of the spinal cord, which adjusts the function of afferent pain fibers [4].

Clonidine, a selective alpha two agonist agent, routinely used as a premedication for general anesthesia decreases the requirement of analgesics and anesthetic drugs intraoperative. Intrathecal clonidine produces analgesia by indirectly inhibiting the activity of wide dynamic range (WDR) neurons [5]. 
Clonidine produces spinal cholinergic activation. Cholinergic interaction in spinal alpha two adrenergic receptors which are located on descending nor-adrenergic pathways produces noradrenaline release that causes analgesia directly, and also it releases acetylcholine to provide analgesia. Clonidine also has an intrinsic block of A delta and C-fibers at lamina, utilizing that, generating analgesia [6].

Clonidine has been used by oral, epidural, spinal, perneural and parenteral routes to achieve postoperative analgesia [7].

Neostigmine is an anticholinesterase agent which increases the acetylcholine concentrations at cholinergic synapses. Spinal neostigmine activates descending pain inhibitory systems that rely on a spinal cholinergic interneuron, probably exacerbating cholinergic tonus that is already activated during the postoperative period, and seems to be extremely efficient for soothing somatic pain [8].

But intrathecal administration of neostigmine causes well-known complications of nausea and vomiting postoperatively due to a rostral spread of neostigmine to brainstem site [9].

\section{Subjects and Methods}

\subsection{Ethics Committee}

After achieving approval by the Benha University Hospital Ethics Committee, and written informed consent from the patient, this study was conducted on 100 patients their ages ranged between 18 and 65 years old, ASA grade I and II of both sexes, from February 2018 to February 2019, randomization was done into four equal groups by lottery method. These patients were scheduled for elective lower abdominal surgeries. All cases were done in Benha University Hospitals after agreed consent of the patients.

\subsection{Type of Study}

A prospective, comparative, double-blind, randomized clinical study.

\subsection{Inclusion Criteria}

1) ASA physical status classes I, II.

2) Age range between 18 - 65years.

3) Type of operation lower abdominal surgeries.

4) Patients were giving valid informed consent.

\subsection{Exclusion Criteria}

Patient refusal:

1) Age $<18$ or $>65$ years;

2) Infection at the site of the injection;

3) Any preexisting neurological disease;

4) The patients with a known history of allergy to local anesthetics drugs;

5) Failed spinal anesthesia;

6) Obese Patients BMI > 30; 
7) Known to be a cardiac patient;

8) Known to be a Diabetic patient;

9) Known to be Hypertensive patient;

10) Patients were receiving any anticoagulant.

\subsection{Group Allocation}

Patients were randomly divided into four-study groups of 25 patients each as per computer-generated random number list. The name of the drug to be given was sealed in envelopes numbered 1 - 100, which was opened by an anesthesiologist not included in the intraoperative and postoperative care of the patient and prepared in an unlabeled $3 \mathrm{ml}$ syringe. This was then handed over to the attending anesthesiologist in a coded form who was blind to the nature of drug given.

100 patients will be randomly divided into four equal groups:

Group I: intrathecal bupivacaine (control group) (B), Group B ( $\mathrm{n}=25$ ) patients will receive $2.5 \mathrm{ml}$ of $0.5 \%$ hyperbaric bupivacaine with $0.5 \mathrm{ml}$ of normal saline.

Group II: intrathecal bupivacaine and fentanyl (BF).

Group BF $(\mathrm{n}=25)$ patients will receive $2.5 \mathrm{ml}$ of $0.5 \%$ hyperbaric bupivacaine with (25 mics) of fentanyl.

Group III: intrathecal bupivacaine and clonidine (BC).

Group BC $(\mathrm{n}=25)$ patients will receive $2.5 \mathrm{ml}$ of $0.5 \%$ hyperbaric bupivacaine with $0.5 \mathrm{ml}$ (75 mic) of clonidine.

Group IV: intrathecal bupivacaine and neostigmine (BN).

Group BN $(\mathrm{n}=25)$ patients will receive $2.5 \mathrm{ml}$ of $0.5 \%$ hyperbaric bupivacaine along with $0.1 \mathrm{ml}$ of neostigmine (50 mics) and $0.4 \mathrm{ml}$ of normal saline.

They will be compared with regards to sensory characteristics, motor characteristics, hemodynamic stability, and any complications.

\subsection{Methodology}

Anesthetic management:

All patients were evaluated one day before surgery initially by medical history and a complete physical examination; routine preoperative investigations were done (e.g. CBC, PT, PTT, INR, liver function tests, kidney function tests, and ECG). Patients were instructed about the use of a visual analogue scale (VAS) preoperatively as a tool for measuring postoperative pain.

Preoperatively adequate fasting was confirmed, and baseline heart rate and blood pressure were noted. These patients were premedicated with tablet ranitidine $150 \mathrm{mg}$ and after shifting the patient to the operation theater, before insertion of intravenous (IV) cannula, baseline parameters such as heart rate (HR), systolic blood pressure (SBP), diastolic blood pressure (DBP), respiratory rate (RR), peripheral oxygen saturation $\left(\mathrm{SpO}_{2}\right)$, and ECG were recorded. After achieving an IV access, preloading was done with $10 \mathrm{ml} / \mathrm{kg}$ of lactated Ringer's solution over 15 - $20 \mathrm{~min}$, under aseptic precautions, and the patient in setting 
position. The skin of the back of the patient was prepared with an iodine-containing sterilizing solution, then the L3-4, L4-5 interspace was detected by palpation, as the highest point of iliac crest is corresponding to the level with the spinous process of the fourth lumbar vertebrae. The midline skin is anesthetized with $1 \%$ percent lidocaine $1 \mathrm{ml}$ by $25 \mathrm{~g}$ needle at a midpoint between the adjacent two vertebrae. The needle was inserted and introduced under the skin until the interspinous ligament was reached which was confirmed by firm resistance then further introduced needle until passing the ligament flavum (that was detected by sudden loss of strength) and the flow of CSF was observed, Following further aspiration, application of the recommended intrathecal drug was made in the selected interspace; the drug is injected slowly over 10 to $15 \mathrm{sec}$. Then the patient was allowed to lye down in supine position with the head slightly elevated.

After the block and during the surgery, including heart rate (HR), noninvasive arterial blood pressure, electrocardiogram (3 leads), and peripheral oxygen saturation (SpaO2), a nasal cannula was applied and supplemental oxygen given during the procedure at $3 \mathrm{~L} / \mathrm{min}$.

Sensory block was assessed bilaterally using 25 gauge hypodermic needle. The onset of sensory block was considered as the time taken from intrathecal injection to the highest level of the sensory block. The duration of sensory block was made from the time of intrathecal injection to regression of the level of sensory block to L1 dermatome (level assessed by re-appearance of sensation on heel and sole of the foot). The onset of motor block was defined as when a modified Bromage score was three or lesser10. Duration of motor block was noted from onset time to time when the patient can afford to lift the extended leg. Sensory characteristics, were evaluated by using pin prick method, and motor characteristics, were evaluated by modified Bromage scale.

The duration of complete analgesia was taken from the time of intrathecal drug administration to the first report of pain. The duration of effective analgesia is from the time of intrathecal drug administration to the time of the early supplementation with rescue analgesic. Injection diclofenac sodium $1.0 \mathrm{mg} / \mathrm{kg}$ intravenous was the rescue analgesic given.

Surgery was allowed to commence on achieving adequate sensory block height (T6-4). Sensory block was recorded 5, 10, and $15 \mathrm{~min}$ after intrathecal injection and then, every $15 \mathrm{~min}$. In the postoperative period, motor block recovery, and sensory block regression were assessed during surgery.

Systolic blood pressure, DBP, HR, and SpO2 were recorded 5 min before intrathecal injection, 5, 10, 15, 20, and 25 min after intrathecal injection and then, at 30, 60 and $90 \mathrm{~min}$ for the duration of surgery

At the end of the operation, patients were transferred to the post-anesthesia care unit (PACU) where monitoring was continued. Postoperatively, monitoring of vital signs, VAS scores, and sedation scores was continued until the time of regression of sensory block to L1 dermatome. The incidence of hypotension (arterial blood pressure $<20 \%$ of baseline), bradycardia (heart rate $<50$ beats $/ \mathrm{min}$ ), 
pruritus, nausea, vomiting, and urinary retention were monitored in the recovery room and then transferred to the ward.

The anesthesiologist who performed subarachnoid block was not included in the assessment of patients and observers were blinded. The Statistical software namely SPSS 17.0, Stata 8.0, were used for the analysis of the data and Microsoft Word and Excel have been used to produce graphs, tables, etc.

Pain scores using VAS were assessed in the PACU at $0,1,2,3,4,8,12,18$, and $24 \mathrm{~h}$. Patients had been informed before surgery that they could request an analgesic when they felt pain in the postoperative period. Any patient reporting VAS $\geq 5$ was administered a supplemental dose of analgesic Injection diclofenac sodium $1.0 \mathrm{mg} / \mathrm{kg}$ IV. The total number of patients who were managed analgesic was noted in each group. Any patient with failed spinal anesthetic or patient complaining of pain in the intraoperative period, which required administration of general anesthesia, was excluded from the study.

All data were analyzed using SPSS 20.0 for windows (SPSS Inc., Chicago, IL, USA). Continuous variables were expressed as the mean \pm SD \& median (range), and the categorical variables were expressed as a number (percentage). Continuous variables were checked for normality by using Shapiro-Wilk test. One way ANOVA was used to compare normally distributed variables between four groups while Kraskall Wallis $\mathrm{H}$ test was used for non-normally distributed variables. Independent samples Student's t-test was used to compare two groups of normally distributed data while Mann Whitney $U$ test was used for non-normally distributed data. All tests were two tailed. P-value $<0.05$ was considered statistically significant $(\mathrm{S}), \mathrm{P}$-value $<0.01$ was considered highly statistically significant (HS), and P-value $>0.05$ was considered statistically insignificant (NS).

\section{Results}

In the current study; One hundred patients were randomly divided into four equal groups each group were 25 patients

There were no significant differences between the four groups regard to age, height, and body mass index, sex (male or female) and ASA grade (I or II) (Table 1).

There were significant differences detected between the four groups regard to Onset of sensory blocks mean and stander deviation in group B $150.40 \pm 28.35$, $\mathrm{BF} 137.20 \pm 29.65, \mathrm{BC} 134.40 \pm 29.73, \mathrm{BN} 120.00 \pm 30.00$ as a $\mathrm{P}$ value $<0.05$ as shown in Table 2 and Figure 1.

There were no significant differences between the four groups regard to Onset of motor blocks means and stander deviation in group B $241.20 \pm 56.52,232.80$ $\pm 61.07, \mathrm{BC} 234.40 \pm 51.57, \mathrm{BN} 230.40 \pm 47.74$ as $\mathrm{P}$ value $>0.05$ as shown in $\mathrm{Ta}-$ ble 2 .

On comparing the four studied groups as regards the duration of analgesia, There was a highly significant difference between four groups sees to duration of analgesia being the bupivacaine clonidine the longest duration of analgesia as 
Table 1. Comparison between the studied groups regarding socio-demographic data.

\begin{tabular}{|c|c|c|c|c|c|c|}
\hline & \multicolumn{4}{|c|}{ Total studied group $n=100$} & \multirow[b]{2}{*}{ F test } & \multirow[b]{2}{*}{ P Value } \\
\hline & $\begin{array}{c}\text { B } \\
n=25\end{array}$ & $\begin{array}{c}\text { BF } \\
n=25\end{array}$ & $\begin{array}{c}\text { BC } \\
n=25\end{array}$ & $\begin{array}{c}\mathrm{BN} \\
\mathrm{n}=25\end{array}$ & & \\
\hline \multicolumn{7}{|l|}{ Age } \\
\hline Mean \pm SD & $45.52 \pm 8.96$ & $43.20 \pm 9.39$ & $45.36 \pm 9.15$ & $44.12 \pm 9.91$ & 0.343 & $0.794 \mathrm{NS}$ \\
\hline \multicolumn{7}{|l|}{ Height $(\mathrm{cm})$} \\
\hline Mean \pm SD & $164.36 \pm 8.33$ & $163.36 \pm 8.37$ & $163.72 \pm 8.29$ & $163.12 \pm 8.00$ & 0.066 & $0.978 \mathrm{NS}$ \\
\hline \multicolumn{7}{|l|}{ BMI } \\
\hline Mean \pm SD & $28.48 \pm 2.04$ & $28.68 \pm 2.59$ & $28.56 \pm 2.34$ & $28.36 \pm 3.34$ & 0.107 & $0.956 \mathrm{NS}$ \\
\hline \multicolumn{7}{|l|}{ Sex } \\
\hline male & $16(64 \%)$ & $14(56 \%)$ & $13(52 \%)$ & $13(52 \%)$ & 0.974 & 0.808 \\
\hline female & $9(36 \%)$ & $11(44 \%)$ & $12(48 \%)$ & $12(48 \%)$ & & NS \\
\hline \multicolumn{7}{|l|}{ ASA } \\
\hline I & $13(52 \%)$ & $15(60 \%)$ & $18(72 \%)$ & $18(72 \%)$ & 3.886 & 0.692 \\
\hline II & $12(48 \%)$ & $10(40 \%)$ & $7(28 \%)$ & $7(28 \%)$ & & NS \\
\hline
\end{tabular}

$\mathrm{F}=$ ANOVA test (analysis of variance); $\mathrm{NS}=$ non-significant.

Table 2. Comparison between the studied groups regarding the onset of motor and sensory block.

\begin{tabular}{|c|c|c|c|c|c|c|}
\hline & \multicolumn{4}{|c|}{ total studied group $n=100$} & \multirow[b]{2}{*}{ Test F } & \multirow[b]{2}{*}{$P$ value } \\
\hline & $\begin{array}{c}\text { B } \\
\mathrm{n}=25\end{array}$ & $\begin{array}{c}\text { BF } \\
\mathrm{n}=25\end{array}$ & $\begin{array}{c}\text { BC } \\
\mathrm{n}=25\end{array}$ & $\begin{array}{c}\text { BN } \\
\mathrm{n}=25\end{array}$ & & \\
\hline \multicolumn{7}{|c|}{ Onset of sensory block/sec. } \\
\hline Mean \pm SD & $150.40 \pm 28.35$ & $137.20 \pm 29.65$ & $134.40 \pm 29.73$ & $120.00 \pm 30.00$ & 4.48 & $0.005 \mathrm{NS}$ \\
\hline \multicolumn{7}{|c|}{ Onset of motor block/sec. } \\
\hline Mean \pm SD & $241.20 \pm 56.52$ & $232.80 \pm 61.07$ & $234.40 \pm 51.57$ & $230.40 \pm 47.74$ & 0.181 & $0.909 \mathrm{NS}$ \\
\hline
\end{tabular}

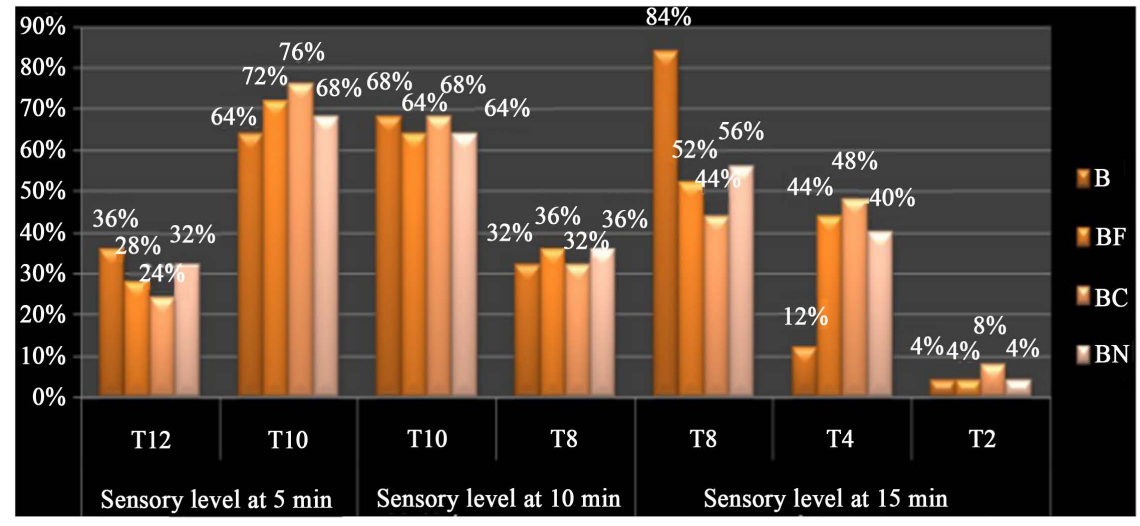

Figure 1. Comparison between the studied groups regarding a sensory level.

mean and stander deviation $238.00 \pm 125.79$ (Table 3).

On comparing the four studied groups as regards the conscious level at 5, 10, and 15 minutes after block there was no significant difference among the four groups, as $\mathrm{P}$ value $>0.05$ (Figure 2 ). 


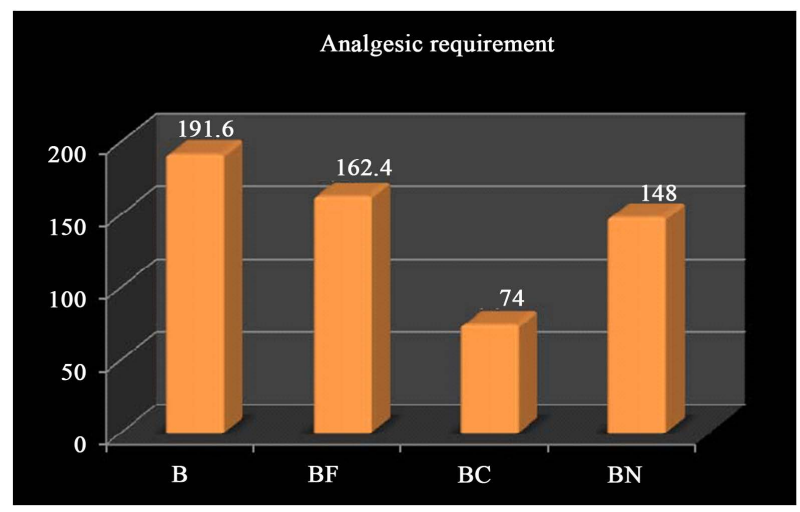

Figure 2. Comparison between the studied groups regarding analgesic requirements.

Table 3. Comparison between the studied groups regarding the duration of analgesia.

\begin{tabular}{|c|c|c|c|c|c|c|}
\hline & \multicolumn{4}{|c|}{ Total studied group $n=100$} & \multirow{2}{*}{$\begin{array}{c}\text { Test } \\
\mathrm{K}\end{array}$} & \multirow{2}{*}{$\begin{array}{c}\mathrm{P} \\
\text { Value }\end{array}$} \\
\hline & $\begin{array}{c}\text { B } \\
\mathrm{n}=25\end{array}$ & $\begin{array}{c}B F \\
n=25\end{array}$ & $\begin{array}{c}\mathrm{BC} \\
\mathrm{n}=25\end{array}$ & $\begin{array}{c}\mathrm{BN} \\
\mathrm{n}=25\end{array}$ & & \\
\hline \multicolumn{7}{|l|}{$\begin{array}{l}\text { Duration of } \\
\text { analgesia } \\
(\mathrm{min})\end{array}$} \\
\hline Mean \pm SD & $60.00 \pm 11.70$ & $72.60 \pm 13.93$ & $238.00 \pm 125.79$ & $67.40 \pm 15.42$ & 53.42 & $<0.001 \mathrm{HS}$ \\
\hline
\end{tabular}

$\mathrm{K}=$ Kruskal Wallis test.

There was a highly significant difference between four groups regards to requirements of analgesia, being the bupivacaine clonidine the lowest elements of analgesia as mean and stander deviation $74.0 \pm 34.4$, and the most requirements of analgesia as in group B $191.6 \pm 51.3$ (Figure 3 ).

On comparing the four studied groups as regards the visual analogue scale (Figure 4) it showed no statistically significant difference at baseline, $1 \mathrm{~h}$, and, 2 $\mathrm{h}$, between 4 groups. There were significantly different at three $\mathrm{h}$, and four $\mathrm{h}$, between B \& BC, BF \& BC, BC \& BN. There was a highly significant difference at eight h, 12 h, 18 h and 24 hours between B \& BC. There was a significant difference at eight h, $12 \mathrm{~h}, 18 \mathrm{~h}$ and 24 hours between BF \& BC, and BC \& BN. There was no statistically significant difference at $8 \mathrm{~h}, 12 \mathrm{~h}, 18 \mathrm{~h}$, and 24 hours between $\mathrm{B} \& \mathrm{BF}, \mathrm{B} \& \mathrm{BN}, \mathrm{BF} \& \mathrm{BN}$.

On comparing the four studied groups as regards the mean arterial pressure (Figure 5), there was no statistically significant difference at baseline, $5 \mathrm{~min}, 60$ min, $90 \mathrm{~min}$ and $120 \mathrm{~min}$ postoperative.

But it showed significantly difference at:

10 min: between $B$ \& BC;

15 min: between B \& BC, BF \& BC, BC \& BN;

20 min: between $B \& B C, B F \& B C, B C \& B N$;

25 min: between $\mathrm{B} \& \mathrm{BC}, \mathrm{BF} \& \mathrm{BC}, \mathrm{BC} \& \mathrm{BN}$;

30 min: between BF \& BC, BC \& BN.

But it showed a highly significant difference at: 


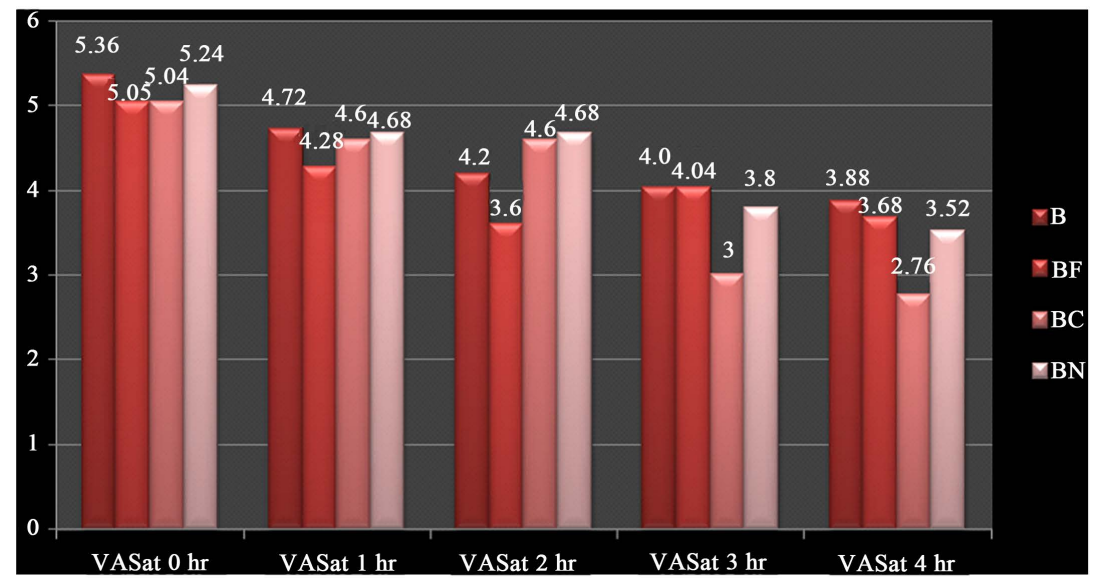

Figure 3. Comparison between the studied groups regarding visual analogue scale.

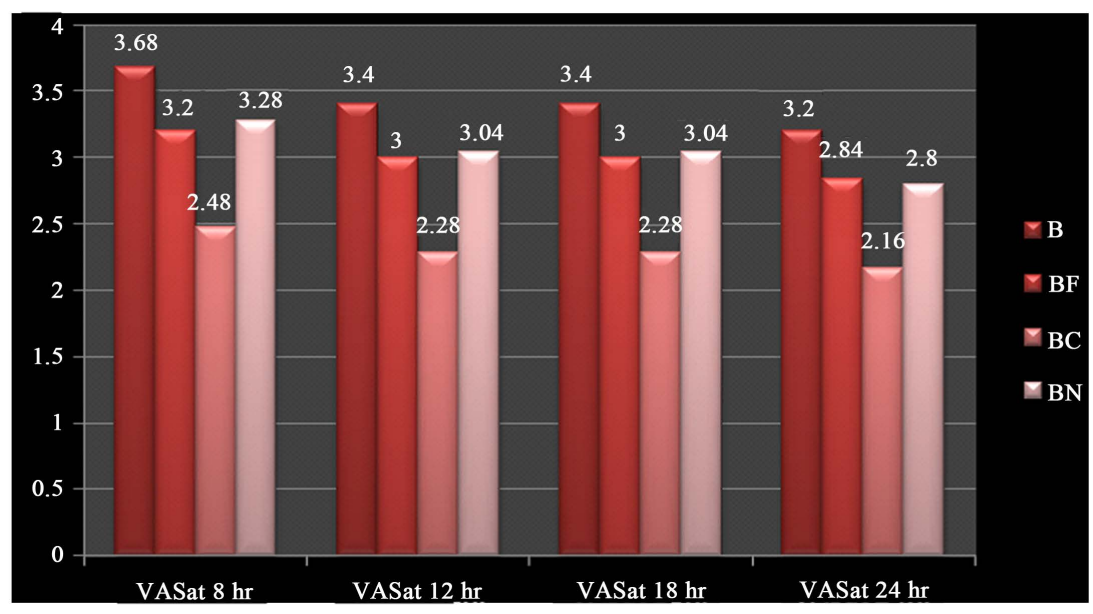

Figure 4. Comparison between the studied groups regarding visual analogue scale (VAS).

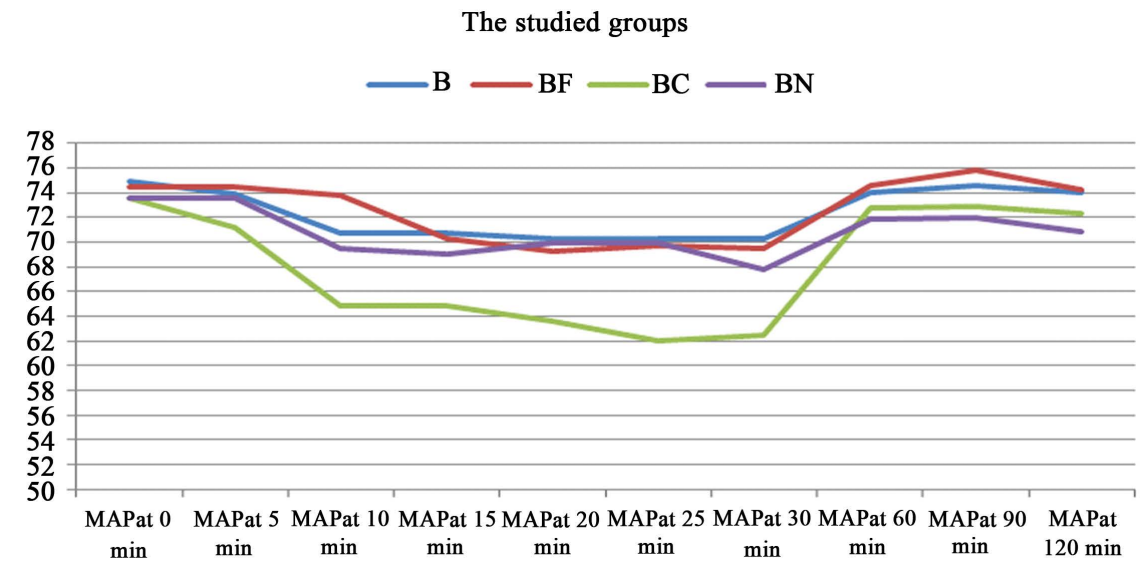

Figure 5. Comparison between the studied groups regarding mean arterial blood pressure (MAP).

10 min: between BF \& BC;

30 min: between B \& BC.

On comparing the four studied groups as regards the heart rate (Figure 6): 


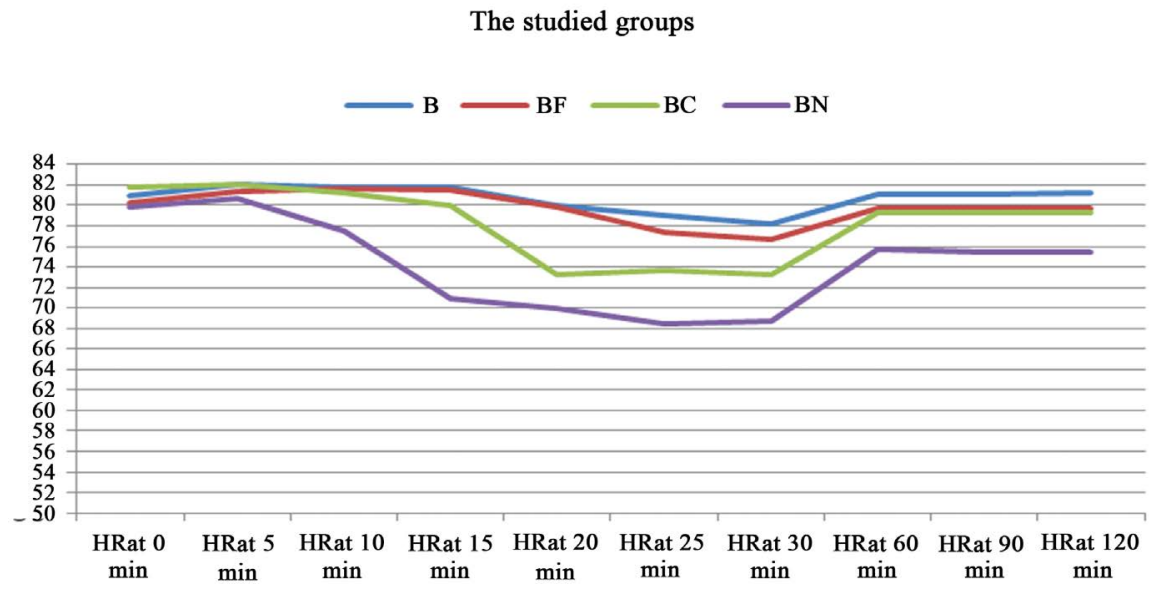

Figure 6. Comparison between the studied groups regarding heart rate (HR).

There was no statistically significant difference at baseline, basal line, $5 \mathrm{~min}$, $10 \mathrm{~min}, 60 \mathrm{~min}$ and $90 \mathrm{~min}$ postoperative.

But it showed a significant difference at:

15 min: between $\mathrm{BF} \& \mathrm{BN}$ and $\mathrm{BC} \& \mathrm{BN}$;

20 min: between $\mathrm{BF} \& \mathrm{BN}, \mathrm{BF} \& \mathrm{BC}, \mathrm{B} \& \mathrm{BN}$ and $\mathrm{B} \& \mathrm{BC}$;

25 min: between $B F \& B N, B C \& B N$ and $B \& B C$;

30 min: between $B C \& B N$, and $B \& B C$;

120 min: between B \& BN;

But it showed a highly significant difference at:

15 min: between $B \& B N$;

25 min: between $B$ \& BN;

30 min: between $B \& B N$ and $B F \& B N$.

On comparing the four studied groups as regards to hypotension (Figure 7), there was significant difference as $\mathrm{P}$ value $<0.05$, group B: 4 patients, group BF: 3 patients, group BC: 6 patients, group 18 patients. High incidence occurred with clonidine.

On comparing the four studied groups as regards vomiting (Figure 8), there was a significant difference among the four groups as a $\mathrm{P}$ value $<0.05$, group B: 1 patient, group BF: 2 patients, group BC: 5 patients, group 12 patients, high incidence occurred with neostigmine.

On comparing the four studied groups as regards nausea (Figure 9), there was a significant difference among the four groups as a $\mathrm{P}$ value $<0.05$, group B3 patients, group BF: 2 patients, group BC: 6 patients, group 10 patients, high incidence occurred with neostigmine.

\section{Discussion}

This study was held in Benha University Hospital; to compare between intrathecal injection of bupivacaine alone or with fentanyl, clonidine, and neostigmine in lower abdominal surgeries. Spinal anesthesia is a favorite anesthesia technique for lower abdominal surgeries. Even though it provides effective analgesia 


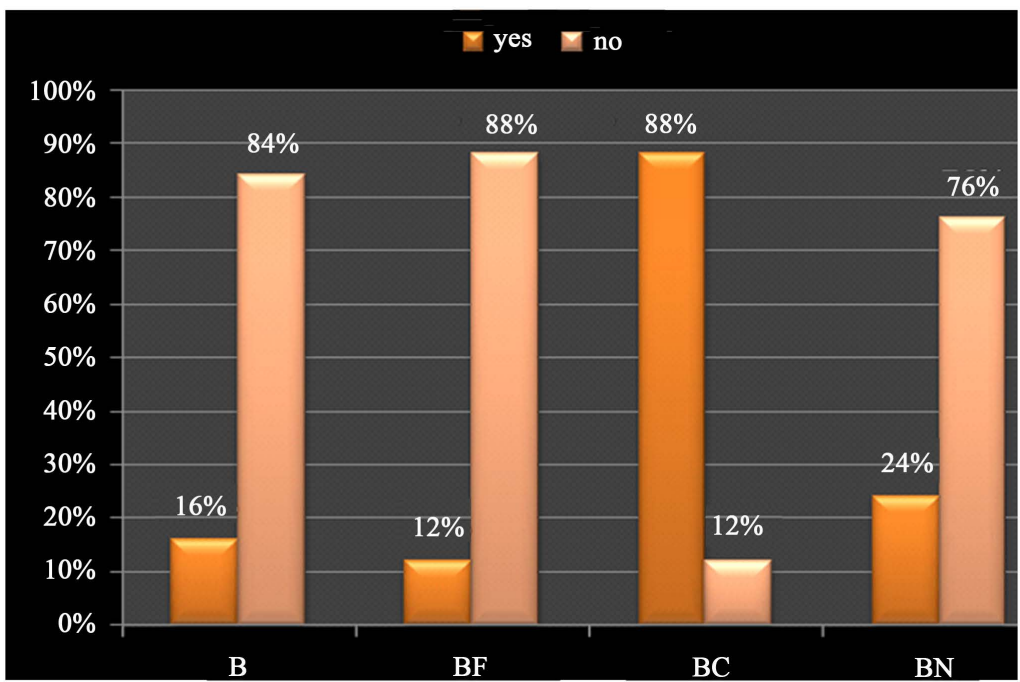

Figure 7. Comparison between the studied groups regarding adverse effects (hypotension).

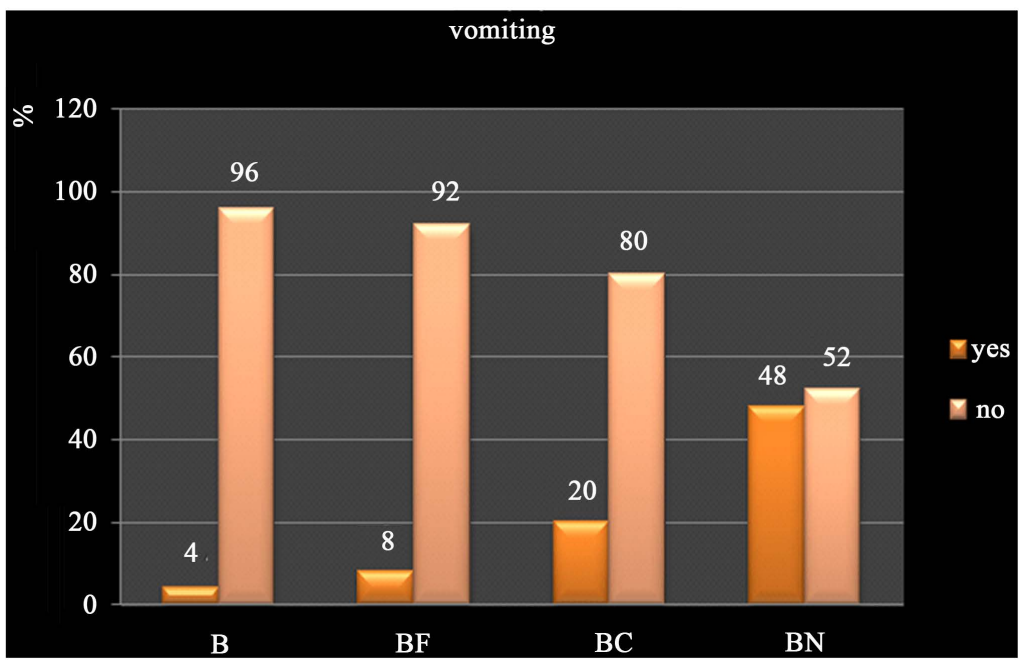

Figure 8. Comparison between the studied groups regarding adverse effects (vomiting).

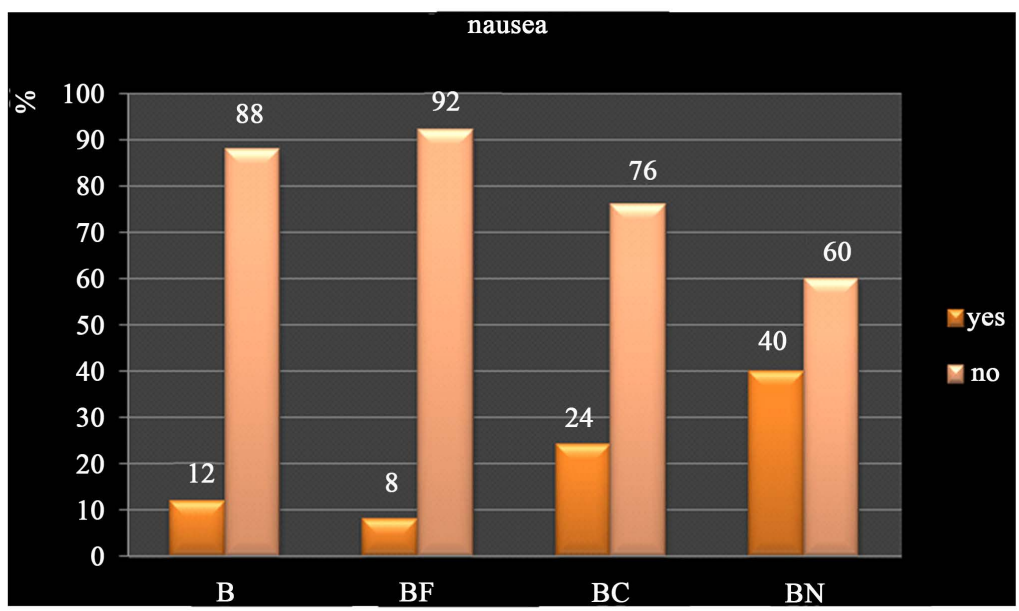

Figure 9. Comparison between the studied groups regarding adverse effects (nausea). 
in the initial postoperative period, this effect is very short lasting. In the context of "Augmentation strategies" for intrathecal analgesia, the discovery of opioid receptors and the following development of the technique of epidural and intrathecal opioid administration is certainly one of the most significant advances in pain management in the last three decades. A wide variety of non-opioids have also been used in epidural or subarachnoid space to achieve pain relief without the risk of respiratory depression [10] [11].

Opioid receptors were detected in the central nervous system in 1971 [12] later, in 1977; these receptors were precisely localized in the posterior horn of the spinal cord [13]. The effectiveness of intrathecal opioids relies on their bioavailability. Penetration into medullary tissue is affected by their molecular weight, a degree of ionization, and lipophilicity. Fentanyl and pethidine are absorbed more rapidly than morphine for these reasons. They bind more firmly to neural tissue. Clearance depends on diffusion along the neuraxis, as well as vascular absorption. The drug reaches the cerebellomedullary cistern via distribution where it is absorbed by the arachnoid granulations. This is especially true in the case of morphine.

The present study was conducted on 100 patients of both sexes 18 to 65 years old, with ASA physical status I or II, who were scheduled for lower abdominal procedures. All patients received intrathecal anesthesia. The patients were fortuitously divided into four groups:

Group I: intrathecal bupivacaine (control group) (B), group B $(\mathrm{n}=25)$ patients will receive $2.5 \mathrm{ml}$ of $0.5 \%$ hyperbaric bupivacaine with $0.5 \mathrm{ml}$ of normal saline.

Group II: intrathecal bupivacaine and fentanyl (BF).

Group BF $(\mathrm{n}=25)$ patients will receive $2.5 \mathrm{ml}$ of $0.5 \%$ hyperbaric bupivacaine with (25 mics) of fentanyl.

Group III: intrathecal bupivacaine and clonidine (BC).

Group BC $(\mathrm{n}=25)$ patients will received $2.5 \mathrm{ml}$ of $0.5 \%$ hyperbaric bupivacaine with $0.5 \mathrm{ml}$ ( $75 \mathrm{mic})$ of clonidine.

Group IV: intrathecal bupivacaine and neostigmine (BN).

Group BN $(\mathrm{n}=25)$ patients will receive $2.5 \mathrm{ml}$ of $0.5 \%$ hyperbaric bupivacaine along with $0.1 \mathrm{ml}$ of neostigmine (50 mics) and $0.4 \mathrm{ml}$ of normal saline.

They were being compared with regards to sensory characteristics, motor characteristics, hemodynamic stability, and drawbacks.

The patients and monitoring anesthesiologist were blinded to the study solutions. As regards the demographic variables there was an insignificant statistical difference among the studied groups. As sees the mean arterial blood pressure among the four groups, there was an insignificant statistical difference at baseline, 60, 90 and 120 minutes after the block and the statistically significant difference was found at 5, 10, 15, 20, 25 and 30 minutes after injection. The decrease in mean arterial blood pressure (MAP) was pronounced in group BC (bupivacaine-clonidine) followed by BF (bupivacaine-fentanyl) group. It could be 
explained as clonidine inhibits sympathetic preganglionic activity in the spinal medulla, by means of that, producing a reduction in arterial blood pressure. The severity of the arterial hypotension seems to be related to the level of the injection as well as with the drug dose used. In addition, the activation of the alph2-postsynaptic receptors in the brain stem along with the peripheral alph2-presynaptic receptors contributes towards an even greater decrease in arterial blood pressure by reducing sympathetic activity [14].

As regards the need for ephedrine, there was a statistical difference in the use of ephedrine, among the four groups. The highest number of patients who required small titration (6 - $15 \mathrm{mg}$ ) of ephedrine was in (bupivacaine-clonidine) group was 22 patients. The lowest number was in (bupivacaine-fentanyl) was three patients

As regards the heart rate changes assessment among the studied groups, there was an insignificant statistical decrease at baseline, 5, 10, 60 and 90 minutes after injection. But their significant statistical reduction was noticed at 15, and 20 minutes after injection. There was highly substantial statistical decrease at 30 minutes difference was seen between $\mathrm{BN}$ group and the other three groups as the heart rate decrease all over the study in Neostigmine group but, not below 70 beats/minutes and did not require any interference.

In addition, the study of heart rate inside each studied group though out the study showed a significant decrease in the heart rate in relation to the baseline which continued for more than 60 minutes after the block. This has appeared in two groups BC \& BN groups.

The occurrence of bradycardia was more in the neostigmine groups though the difference was not statistically significant. All the patients responded to intravenous atropine. Neostigmine 50 ug caused bradycardia at $60-70 \mathrm{~min}$ after administration of spinal anesthesia and bradycardia was successfully treated with atropine.

In view of the time for onset of sensory blockade (sec) and the duration of it (min); in the present study, there was a statistically significant difference among the studied groups. The more rapid onset was noticed in the (bupivacaine-neostigmine). As neostigmine increases action of spinally administered local anesthesia, spinal administration of neostigmine, an acetylcholinesterase inhibitor, inhibits the breakdown of the endogenous neurotransmitter acetylcholine, thereby inducing analgesia, hence it is another alternative nonopioid additive to local anesthetics devoid of opioid-associated side effects. And the longest duration of sensory blockade was noticed in the bupivacaine-clonidine) group which could be explained as clonidine produces local vasoconstriction by acting on vascular smooth muscle (alpha receptors), which decreases absorption of local anesthetics from subarachnoid space thereby prolongation the duration of action.

In view of the sedation scale assessment, it showed statistically insignificant differences among the four groups. Only three patients in fentanyl group and two patients clonidine group reached level 3, and two patients in neostigmine group achieved level 2 sedation, and they were easily aroused. this could be ex- 
plained by the variability in length and drug response between the patients.

This was in agreement with the study of who studied the combination of intrathecal bupivacaine with fentanyl in different doses and found that dose of fentanyl in a treatment of $25 \mathrm{ug}$ did not produce significant sedation [15].

As regards the visual analogue score (VAS), There was a statistically significant difference among the four groups. The most powerful analgesic agent is intrathecal clonidine combined with bupivacaine followed by bupivacaine-fentanyl. There was also the time-related decrease in VAS in relation to the baseline in each studied group (inside each group, in the four groups) started with the onset of action of analgesia and continued throughout the time of the study.

As regards adverse effects hypotension most occurred in a group (bupivacaine-clonidine), nausea and vomiting most happened in a group (bupivacaine-neostigmine). That also is in the study done by [16]. There was significant difference in nausea where group (bupivacaine-neostigmine) $\mathrm{BN}$ had the highest incidence (10 patients) and the lowest incidence with (bupivacaine-fentanyl) group ( 2 patients) the nausea was mild and responding well to the second dose of metoclopramide $10 \mathrm{mg}$. However, in Gupta S study, hypotension in the group receiving neostigmine 75 ug was more than the other group receiving 50 ug.

Intrathecal neostigmine causes nausea in a dose-dependent manner. This high occurrence of nausea and vomiting could be due to cephalad migration of neostigmine to the brain stem where it produces an accumulation of acetylcholine. This increased acetylcholine leads to vomiting by stimulating the chemoreceptor trigger zone. The injection of neostigmine in hyperbaric dextrose solution while maintaining the patient in head up position reduces the incidence of vomiting [17].

In another study show that the administration of intrathecal neostigmine 25 $\mathrm{ug} / \mathrm{kg}$ with bupivacaine leads to increased the duration of sensory, motor block and also time to the first rescue of analgesia compared to the control group after lower limb surgeries [18].

This is a present study in agreement with a study done by Kothari et al., that found $35 \%$ to $45 \%$ of patients drowsy by addition of 50ug of clonidine to bupivacaine [19].

Also, this study in agreement with another research which studies the effect of intrathecal fentanyl (12 - $25 \mathrm{ug}$ ) when added to different doses of bupivacaine (3 - $5 \mathrm{mg}$ ) in postoperative analgesia for knee arthroscopy, that found the addition of fentanyl lead to decrease the failure rate and improve the visual analogue score $[20]$.

\section{Conclusion}

Bupivacaine-clonidine mixture had the longest duration of analgesia, but with an increased incidence of hypotension. So bupivacaine-fentanyl mixture with moderate duration of analgesia and fewer complications is the safest for the patients. 


\section{Conflicts of Interest}

The authors declare no conflicts of interest regarding the publication of this paper.

\section{References}

[1] Agarwal, K.K. (2009) Complications and Controversies of Regional Anaesthesia: A Review. Indian Journal of Anaesthesia, 53, 543-553.

[2] Shah, B.B., Shidhaye, R.V., Divekar, D.S., Panditrao, M., Panditrao, M.M. and Suryawanshi, C. (2011) Effect of Addition of Clonidine to Bupivacaine Used for Patients Undergoing Spinal Anesthesia: A Randomized, Double-Blind, Controlled Study. Sri Lankan Journal of Anaesthesiology, 19, 17-21. https://doi.org/10.4038/slja.v19i1.1715

[3] Yoganarasimha, N., Raghavendra, T.R., Amitha, S., Shridhar, K. and Radha, M.K. (2014) Comparative Study between Intrathcal Clonidine and Neostigmine with Intrathcal Bupivacaine for Lower Abdominal Surgeries. Indian Journal of Anaesthesia, 58, 43-47. https://doi.org/10.4103/0019-5049.126794

[4] Negi, A.S., Gupta, M. and Singh, A. (2015) Comparison of the Effect of Intrathecal Buprenorphine vs. Clonidine as an Adjuvant to Hyperbaric Bupivacaine on Subarachnoid Block Characteristics. Journal on Recent Advances in Pain, 1, 67-72.

https://doi.org/10.5005/jp-journals-10046-0014

[5] Van Tuijl, I., Giezeman, M.J., Braithwaite ite, S.A., Hennis, P.J., Kalkman, C.J. and van Klei, W.A. (2008) Intrathecal Low-Dose Hyperbaric Bupivacaine-Clonidine Combination in Outpatient Knee Arthroscopy: A Randomized Controlled Trial. Acta Anaesthesiologica Scandinavica, 52, 343-349.

https://doi.org/10.1111/j.1399-6576.2007.01574.x

[6] van Tuijl, I., van Klei, W.A., van der Werff, D.B. and Kalkman, C.J. (2006) The Effect of the Addition of Intrathecal Clonidine to Hyperbaric Bupivacaine on Postoperative Pain and Morphine Requirements after Caesarean Section: A Randomized Controlled Trial. British Journal of Anaesthesia, 97, 365-370. https://doi.org/10.1093/bja/ael182

[7] Strebel, S., Gurzeler, J.A., Schneider, M.C., Aeschbach, A. and Kindler, C.H. (2004) Small-Dose Intrathecal Clonidine and Isobaric Bupivacaine for Orthopaedic Surgery: A Dose Response Study. Anesthesia \& Analgesia, 99, 1231-1238. https://doi.org/10.1213/01.ANE.0000133580.54026.65

[8] Kayalha, H., Mousavi, Z.S., Barikkani, A., Yaghoobi, S. and Khezri, M.B. (2015) The Effects of Itrathecal Neostigmine Added to Bupivacaine on a Postoperative Analgesic Requirement in Patients Undegoing Lower Limb Orthopedic Surgery. Middle East Journal of Anesthesiology, 23, 199-204.

[9] Pandev, V., Mohindra, B.K. and Sodhi, G.S. (2016) Comparative Evaluation of Different Doses of Intrathecal Neostigmine as an Adjuvant to Bupivacaine for Postoperative Analgesia. Anesthesia: Essays and Researches, 10, 538-545. https://doi.org/10.4103/0259-1162.180779

[10] Brull, R., Macfarlane, A.J.R. and Chan, V.W. (2015) Spinal, Epidural, and Caudal Anesthesia. In: Miller, R.D., Ed., Miller's Anesthesia, 8th Edition, Saunders Elsevier, Philadelphia, 1684-1720.

[11] Elia, N., Culebras, X., Mazza, C., Schiffer, E. and Tramèr, M.R. (2008) Clonidine as an Adjuvant to Intrathecal Local Anesthetics for Surgery: Systematic Review of Randomized Trials. Regional Anesthesia and Pain Medicine, 33, 159-167. 
https://doi.org/10.1016/j.rapm.2007.10.008

[12] Bouaziz, H., Tong, C. and Eisenach, J.C. (1995) Post Operative Analgesia from Intrathecal Neostigmine in Sheep. Anesthesia \& Analgesia, 80, 1140-1144. https://doi.org/10.1097/00000539-199506000-00012

[13] Lirzin, J.D. and Jacquinot, P. (1989) A Controlled Trial of Extradural Bupivacaine with Fentanyl, Morphine or Placebo for Pain Relief in Labor. British Journal of Anaesthesia, 62, 641-644. https://doi.org/10.1093/bja/62.6.641

[14] Josphens, G., Vilaly, C. and Cordin, V. (2001) Alph2 Agonists in Regional Anesthesia. Current Opinion in Anesthesiology, 14, 751-753.

[15] Joshi-Khadke, S.L., Khadke, V.V., Patel, S.J., Borse, Y.M., Kelkar, K.V., Dighe, J.P. and Subhedar, R.D. (2015) Efficacy of Spinal Additives Neostigmine and Magnesium Sulfate on Characteristics of a Subarachnoid Block, Hemodynamic Stability, and Postoperative Pain Relief: A Randomized Clinical Trial. Anesthesia, Essays and Researches, 9, 63-71. https://doi.org/10.4103/0259-1162.150168

[16] Gupta, S. (2010) Postoperative Analgesia with Intrathecal Neostigmine. The Internet Journal of Anesthesiology, 25, 10-13.

[17] Shidhaye, R.V., Shah, B.B., Joshi, S.S., Deogaonkar, S.G. and Bhuva, A.P. (2013) Comparison of Clonidine and Fentanyl as an Adjuvant to Intrathecal Bupivacaine for Spinal Anesthesia and Postoperative Analgesia in Patients Undergoing Caesarian Section. Sri Lankan Journal of Anaesthesiology, 22, 15-20.

https://doi.org/10.4038/slja.v22i1.6158

[18] Hye, M.A., Masud, K.M., Banik, D., Haque, N.F. and Akhtaruzzaman, K.M. (2012) Intrathecal Neostigmine for Postoperative Analgesia in Cesarean Section. Mymensingh Medical Journal, 19, 586-593.

[19] Kothari, N., Bogra, J. and Chaudhary, A.K. (2011) Evaluation of the Analgesic Effect of Intrathecal Clonidine along with Bupivacaine in Cesarean Section. Saudi Journal of Anaesthesia, 5, 31-35. https://doi.org/10.4103/1658-354X.76499

[20] (2016) Practice Guidelines for the Prevention, Detection, and Management of Respiratory Depression Associated with Neuraxial Opioid Administration: An Updated Report by the American Society of Anesthesiologists Task Force on Neuraxial Opioids and the American Society of Regional Anesthesia and Pain Medicine. Anesthesiology, 124, 535-552. https://doi.org/10.1097/ALN.0000000000000975 